\title{
Adhesión bacteriana a biomateriales
}

\author{
Ábalos C*
}

\section{RESUMEN}

En términos generales, para la adhesión bacteriana, influyen cuatro elementos: Material, Microorganismos, antimicrobianos y mecanismos de defensa. La influencia del material es más importante en los estadios iniciales de la adhesión, pudiendo influir el mismo material, su rugosidad o su energía superficial., si es que existe una influencia del material en la adhesión bacteriana, esta reside en las caracteristicas de la película adquirida y en la especificidad de las proteinas adsorbidas salivares (receptores), que puedan ser condicionadas por la composición del material o por las características de superficie de este.

Palabras clave: Adhesion bacteriana, biomateriales, mecanismos de adhesión.

\begin{abstract}
In general terms, there are four elements which influence on bacterial adhesion: the material, the micro organisms, antimicrobials and defence mechanisms.

The influence of the material is more relevant at the initial states of adhesion where the proper material, its roughness or its superficial energy can have some influence.

If there is some influence of the material in the bacterial adhesion, it relies on the features of the acquired film and on the specificity of the adsorved salivary proteins (receptors), which can be influenced by the composition of the material or the characteristics of its surface.
\end{abstract}

Key words: Bacterial adhesion, biomaterials, adhesion mechanisms.

Aceptado para publicación: octubre 2005

* Profesor Asociado. Facultad de Odontología. Universidad de Sevilla.

Ábalos C. Adhesión bacteriana a biomateriales. Av. Odontoestomatol 2005; 21-1: 347-353.

En cualquier sistema de agua corriente, cualquier sólido que esté sumergido en él, tiene en su superficie una rica y variada actividad de microorganismos. La clave para que puedan mantener su actividad estos seres vivos es su capacidad de adhesión. De esta propiedad depende el que puedan fijarse a la superficie y desde esta situación nutrirse y reproducirse, o que sean renovados. Por tanto, este dinamismo en su composición hace que a estos sistemas ecológicos se les denomine abiertos.

En el organismo humano, la única superficie dura natural sumergida en un fluido son los dientes. Sin embargo, en situaciones patológicas las litiasis del sistema urinario o de la vesícula biliar, participan de esta particularidad. Por definición, estas superficies son colonizadas por bacterias que pueden ser responsables de infecciones de repetición e incluso responsables de la pigmentación de estos cálculos (1). También, en situaciones terapeúticas cobra un especial interés la introducción de catéteres intravasculares y su posible colonización posterior por microorganismos.

En nuestro ámbito odontológico al sustitución del tejido dentario por un material restaurador o la colocación de prótesis en la cavidad bucal establecen las condiciones para que estas superficies, al estar sumergidas en un fluido, sean colonizadas por microorganismos. La superficie del material y su composición pueden influir en la capacidad de adhesión de los microorganismos y en la formación más o menos rápida de la placa bacteriana. Es nuestro objetivo acla- 
rar cómo sucede la adhesión bacteriana y la influencia de los distintos biomateriales.

En términos generales, para la adhesión bacteriana, influyen cuatro elementos: Material, Microorganismos, antimicrobianos y mecanismos de defensa (2). Nosotros nos vamos a centrar en relación entre el material y el microorganismo, aunque estos cuatro factores están totalmente interrelacionados. Incluso, en determinadas ocasiones uno de ellos puede enmascarar a los demás. En un estudio donde se medía la distinta capacidad adhesiva de varios microorganismos a materiales colocados en diferentes localizaciones de la cavidad bucal, se observó como independientemente de las distintas variables lo que destacaba era la mayor colonización de las superficies vestibulares que las linguales. Esto es debido a que los mecanismos de autolimpieza son más eficaces por palatino

\section{ADHESIÓN BACTERIANA}

La adhesión bacteriana depende de unos Factores Inespecíficos de índole físico-químicos, eléctricos, etc. Y otros Factores Específicos de carácter adhesina-receptor, fimbrias, etc. De todas formas, en primer lugar para que se produzca la adhesión es necesario que la bacteria se acerque a la superficie del material.

El transporte de la bacteria se produce por tres mecanismos: 1) difusión; 2) dinámica del fluido y 3)

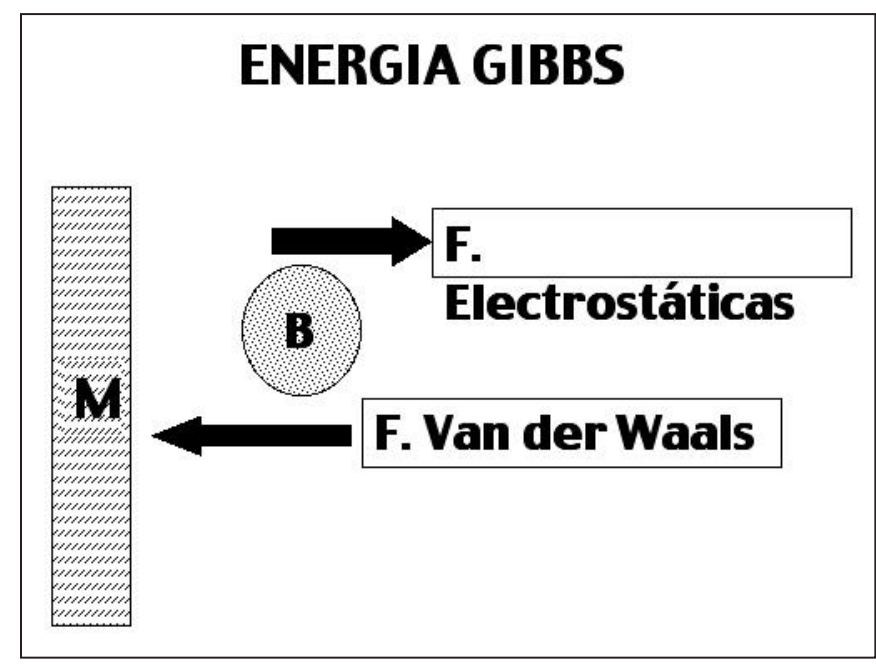

Fig. 1. Mecanismos de la adhesión bacteriana. Energía GIBBS. por actividad propia de la bacteria . No existe ninguna interaccción entre la superficie sólida y el microorganismo hasta una distancia de $50 \mathrm{~nm}$. Cuando la bacteria se acerca a esta distancia aparece una atracción debido a las fuerzas de Van der Waals $(\mathrm{Fa})$, que son debidas a un efecto dipolo entre átomos o moléculas. A medida que se va acercando a la superficie y a una distancia más corta que la interacción por las Fuerzas de Van der Waals, aparece una fuerza de repulsión debida a la carga negativa de la bacteria y del material que suelen ser del mismo signo. A esta fuerza se le denomina " $Z$ potencial" ( $F e)$. De la interacción de estas dos fuerzas es de lo que depende el mayor o menor acercamiento del microorganismo a la superficie del material (Figura 1) y es lo que se denomina Energía Gibbs, expresado en la siguiente fórmula:

$$
\text { Energía Gibbs }=\mathrm{Fa}-\mathrm{Fe}
$$

El Z potencial depende de la carga iónica de la bacteria y de la superficie del material, pero también tiene una influencia el medio iónico en el que están sumergidas estas superficies. Normalmente, alrededor de la bacteria y del material, ambos con carga negativa, se forma una concentración de hidrogeniones del medio salivar para neutralizar la carga. Dependiendo de la ionización del medio se necesitará una capa mayor o menor para neutralizar la carga, obteniendo en las dos superficies una doble capa. Así, en medios iónicos altos la doble capa es muy delgada y permite un mayor acercamiento entre las

\section{FUERZAS DE GRAN ALCANCE}

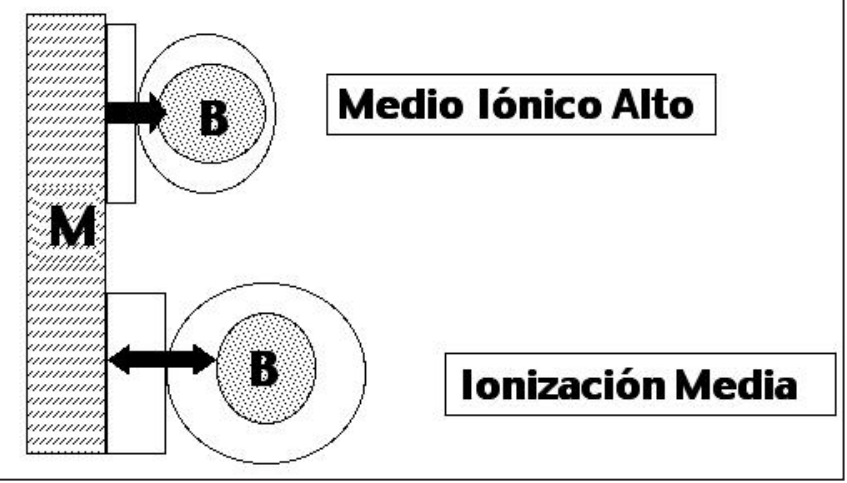

Fig. 2. Mecanismos de la adhesión bacteriana. Fuerzas de gran alcance. 
dos superficies. Sin embargo, en medios iónicos medios o bajos, la doble capa es de mayor grosor y la distancia de la bacteria a la superficie sólida es mayor, ya que la bacteria se detiene cuando las dobles capas entran en contacto (Figura 2).

El resultado de estas interacciones es el mayor o menor acercamiento de la bacteria a la superficie del material. Cuando la bacteria llega a una distancia de 2nm podemos predecir que la adhesión será irreversible, sin embargo a una distancia de $10 \mathrm{~nm}$ la situación es crítica ya que la bacteria dependiendo de su tamaño y otros factores puede adherirse reversible o irreversiblemente. A distancias mayores, la adhesión puede considerarse reversible.

Estas fuerzas que hemos descrito son un modelo de cómo puede ocurrir la adhesión de las bacterias a la superficie dental o a los biomateriales. Se llaman fuerzas de gran alcance y están sometidas a las leyes fisico-químicas. Realmente no sabemos si todo ocurre de esta forma, porque no están totalmente demostrados los mecanismos de la adhesión, pero este modelo según diferentes autores (3) es el que se puede acercar más a la realidad. Esta teoría denominada DLVO debido a las iniciales de los autores que la describieron: Derjaguin, Landau, Verwey y Overbeek, es una hipótesis cualitativa, que describe la posibilidad o no de que la adhesión sea reversible o irreversible, pero en ningún modo nos cuantifica la adhesión.

Una vez que la bacteria esta cerca de la superficie sólida, entran en juego las fuerzas de corto alcance, donde la interacción de fuerzas es sustituida por una serie de fuerzas adhesivas, que tienen un carácter de enlace primario, bien iónico o covalente. Posteriormente, se produce la fijación a la superficie del biomaterial o la superficie dura del diente. Cuando se fijan los microorganismos entran en íntimo contacto con la superficie sólida, ya que la bacteria tiene la capacidad de absorber el medio hídrico que le rodea, debido a grupos hidrofóbicos que ella posee o sus apéndices.. A veces existe una separación entre las dos superficies, pero es debido a los polisacaridos extracelulares fabricados por estos microorganismos.

En la fijación están presenten una serie de mecanis- mos específicos. La superficie del biomaterial o del diente se reviste por una película con componentes salivares que actúan como receptores específicos. Estos receptores pueden ser sacáridos para las adhesinas bacterianas, pero también pueden ser receptores proteináceos para algunas adhesinas como las PRPs ( proteinas salivares ricas en prolina) que solo reconoce el Actinomices Viscosus. Los polisacaridos extracelulares son fabricados por las bacterias debido a la enzima glucosiltransferasa libre o en el interior de la bacteria. Esta enzima tiene la capacidad de metabolizar la sacarosa de la dieta y descomponerla en glucosa y fructosa. A partir de la glucosa pueden establecerse uniones alfa 1-6 ó alfa 1-3, a estos últimos se le denominan mutanos y debido a su carácter insoluble, son fundamentales en los mecanismos de adhesión bacteriana.

En algunas ocasiones, cuando la bacteria esta a una distancia aproximadamente de $10 \mathrm{~nm}$, la bacteria puede unirse íntimamente a la superficie del material debido a sus prolongaciones, fimbrias o pilis, que pueden alcanzar al material o la superficie dentaria. Esto es debido a que las fuerzas de Van der Waals no son influenciadas por el radio del microorganismo, pero las fuerzas electrostáticas sí. Como la fimbria es de un radio muy pequeño las fuerzas de atracción siguen existiendo, pero las electrostáticas de repulsión se minimizan, por lo que la prolongación bacteriana es capaz de alcanzar la superficie sólida, aunque la bacteria no. Por tanto, estas prolongaciones juegan un importante papel en la adhesión bacteriana a distancias mayores de $2 \mathrm{~nm}$.

Una vez formada la pelicula adquirida salival sobre la superficie del diente o del biomaterial y la fijación de la primera capa bacteriana, la posterior colonización y maduración de la placa es un proceso común que en nada se diferencia de la superficie colonizada. Es decir, la maduración de la placa esta condicionada más por factores de localización de la placa (p.e. supragingival o infragingival), que por las características de superficie. En otras palabras, si es que existe una influencia del material en la adhesión bacteriana, esta reside en las caracteristicas de la película adquirida y en la especificidad de las proteinas adsorbidas salivares (receptores), que puedan ser condicionadas por la composición del material o por las características de superficie de este. 


\section{INFLUENCIA DEL BIOMATERIAL}

La controversia surge en la respuesta a una pregunta: ¿Es capaz el material de transmitir sus caracteristicas a la pelicula adquirida?. Puede ocurrir que esta película actúe como amortiguador de las propiedades del material y enmascare sus características, produciéndose una adhesión muy similar en todos los materiales. Existen estudios que apoyan en ambos sentidos.

Hay que decir que la capacidad adhesiva a distintos materiales puede depender de los microorganismos empleados, ya que podemos observar mayor adhesión a un material que a otro y no depender del material, sino del microorganismo. También las condiciones adhesivas pueden variar en el momento de la medida, es un proceso dinámico que puede variar en el tiempo. Los estudios in vitro no reproducen todas las variables de las condiciones reales, con lo que pueden alterar lo que ocurre en la realidad. Para medir la adhesión bacteriana es importante que no se produzca la lisis celular, de ahí la diferencia entre los estudios de inhibición de crecimiento bacteriano y la adhesión bacteriana. Por esta razones y algunas otras es por lo que se justifica la disparidad en los estudios de adhesión bacteriana y la dificultad para dilucidar la verdadera influencia del material.

De todas formas, y dentro de las CARACTERISTICAS DE SUPERFICIE, hemos de hablar de la influencia de la Energía Superficial. La influencia de la energía superficial del substrato puede ser despejada de la fórmula:

Gradiente de Adhesión = IFsb - IFsl -Ifbl $\mathrm{IF}=$ Interfase; $\mathrm{s}=$ substrato; $\mathrm{l}=$ líquido; $\mathrm{b}=$ bacteria

Existen superficies como el acero inoxidable y el oro con una alta energía superficial y otras como las resinas con más baja energía superficial, lo que podría modificar la adhesión bacteriana. Una alta energía superficial del substrato favorecería unas condiciones de hidrofília y una baja energía superficial la hidrofobia. Si la energía superficial de la bacteria es superior que la del medio, la adhesión se ve favorecida por la hidrofilia. Sin embargo, en condiciones de hidrofobia, la energía superficial de la bacteria debe ser menor que la del medio para favorecer la adhesión.
En substratos inertes y en esmalte pulido la energía superficial baja y se ha comprobado que la adhesión para el S. Mitis se ve favorecida por las condiciones hidrofóbicas. Por el contrario, el S, Mutans adhiere mejor en condiciones de hidrofilia. A la vista de estos resultados podemos pensar que existe una vinculación cepa-dependiente para las distintas superficies (4).

De forma general, mientras las bacterias tengan mayor energía superficial existirá mayor adhesión, dado que la saliva tiene baja energía superficial. También, las bacterias con mayor energía superficial tendrán mayor afinidad por substratos con mayor energía superficial y viceversa. Así, la baja energía superficial de los biomateriales reduce la adhesión y retarda por tanto la maduración de la placa.

No obstante, cuando el substrato es revestido por el film proteico, este tiene la cualidad de bajar la energía superficial de aquellos substrato que la tienen alta y subir la de los que la tienen baja. Es decir, tiene un efecto amortiguador que puede enmascarar los efectos del material. El efecto de la película en general es bajar el número de bacterias, independientemente del substrato. La aproximación fisico-química permanece, pero baja.

Otros estudios, confirman que sólo pequeñas diferencias en la película, pero importantes, son cepadependiente. Por ejemplo una rica capa de mucinas, favorece la adhesión del S, mutans y baja la adhesión del S. Sanguis (5). Es decir, estas observaciones pueden confirmar que las propiedades fisico-químicas del substrato pueden ser transferidas a su superficie y alterar la composición, la densidad y la configuración de la película adquirida en cuanto al tipo de proteinas; y por tanto, transferirlas a su vez a la interfase proteinas-células y en consecuencia tener una influencia en la fase inicial de la adhesión. En general falta comprender la importancia real de estos mecanismos.

En cuanto La Rugosidad, como segunda característica de superficie, aquellas superficies más rugosas tienen la capacidad de retener mayor cantidad de placa. Normalmente la acumulación bacteriana empieza por estas áreas debido a que se protegen mejor de los mecanismos naturales de defensa de autolimpieza . Además, al aumentar la rugosidad, aumenta el área de superficie con lo cual se favorece la adhesión. 
El pulido de los materiales en este sentido es esencial para disminuir la adherencia bacteriana. No obstante, debemos tener cuidado con el exceso de pulido en amalgamas, acrílico, etc. Ya que puede aumentar su rugosidad.

En general, la mayoría de los estudios resaltan como los materiales pulidos disminuyen la adhesión bacteriana. Las porcelanas glaseadas y las resinas son las que menor adhesividad manifiestan. Sin embargo, existen materiales como el oro que al pulirlos no es tan manifiesta la disminución de la adhesividad bacteriana. (6)

En estudios realizados (7) para medir la importancia de la energía superficial respecto de la rugosidad, se demuestra que la rugosidad de un material tiene mayor relevancia respecto de la adhesividad bacteriana que la energía superficial.

\section{IOMEROS DE VIDRIO}

En cuanto a los ionómeros de vidrio podemos encontrar estudios, como por ejemplo el de SHAHAL (8), que estudia la adhesividad bacteriana entre los composites y los ionómeros de vidrio. Al revestirlos con saliva fresca de parótida no encuentra diferencias entre ellos. En este caso, la película enmascara las posibles diferencias del material.

Sin embargo en otros estudios, KAWAI (6), encuentra que aunque los ionómeros no bajan la adherencia significativamente al principio, si lo hacían a las 24 horas y en un grado mayor que los compómeros y siempre mayor que los composites.

En general, los ionómeros de vidrio bajan la adhesividad bacteriana debido a su concentración de flúor. In vitro reducían la adherencia para el S. Mutans, S. Mitis, S. Sanguis y Actinomices viscosus en un $80 \%$ y estaba relacionado con la capacidad de liberación de flúor. Puede influir en no reconocer la actividad del flúor, el hecho de que en distintos estudios se lavan las muestras para eliminar las bacterias no adheridas lo que supone también eliminar del medio el flúor (9). Por otra lado, es su rugosidad de superficie lo que puede aumentar la adhesividad bacteria- na, cuando no están bien pulidos o con grietas debido a la dificultad de mantener su equilibrio hídrico.

\section{RESINAS COMPUESTAS}

Los composites no tienen debido a su composición tanta capacidad de inhibición de la adhesión bacteriana como los iónomeros de vidrio. Existen estudios donde al añadir substancias a su composición pueden inhibir la adherencia. Por ejemplo el triclosan añadido a su composición inhibe la adherencia tanto en muestras revestidas, como no revestidas de saliva. (10).

En cuanto al pulido del composite, una resina compuesta rugosa aumenta la adhesión bacteriana, pero cuando se pule el efecto es mayor en las resinas compuestas que en los ionómeros de vidrio, en cuanto a la disminución de la adhesión. (11). Hay gérmenes, como el S. Oralis, que a diferentes grados de rugosidad no variaba su grado de adhesión, ya que esta se producia especificamente a las partículas de relleno. (12).

El efecto de agentes blanqueadores sobre la superficie de los composites, implica un aumento para la adhesión de S. Mutans y sobrinus, tanto con peroxido de carbamida como con peroxido de hidrogeno. Sin embargo, bajaban la adhesividad de A. Viscosus. (13).

\section{AMALGAMA Y ORO}

El acumulo de placa bacteriana es menor para la amalgama, en la mayoría de los estudios que para las resinas compuestas, aunque una resina compuesta muy pulida retiene menos placa que la amalgama. En cuanto a su composición, existen estudios (14) donde amalgamas de alto contenido en cobre pueden inhibir la adherencia de ciertas bacterias como el S. Mitis. Los blanqueamientos pueden alterar la superficie de la amalgama y de las restauraciones metálicas, porque baja la capa de proteinas adsorbidas. Sin embargo, en tratamientos cortos clínicamente no tiene importancia.

El oro retiene menos placa que las amalgamas y que 
los composites. Sin embargo, al pulir todos los materiales, el oro retenía comparativamente mayor placa que la amalgama de plata, resinas compuestas y porcelanas, aunque en general disminuía la adhesión bacteriana para todos los materiales (6). Por tanto, el oro como material presenta menor adherencia bacteriana. Sin embargo, en condiciones optimas de pulido, quizás debido a su alta energía superficial, puede aumentar su adherencia en términos relativos.

\section{PORCELANAS}

Estos materiales son los que menos placa acumulan.(15). Estudios entre porcelanas (6), comparando las nuevas porcelanas con las convencionales, no demuestran diferencias estadísticamente significativas en cuanto a su adhesión bacteriana. Sin embargo, cuando estas porcelanas se tallaban algo con una fresa, la porcelana Dicor presentaba menor adhesión que las porcelánas feldespáticas (Celay), debido a su estructura lineal que minimizaba las rugosidades.

Como conclusión, los mecanismos de la adhesión bacteriana son todavía desconocidos, aunque disponemos de un modelo que se puede acercar bastante a la realidad. Existen muchas variables que en determinadas ocasiones pueden igualar la adhesión bacteriana a materiales con distinta composición o características de superficie. La influencia del material es más importante en los estadios iniciales de la adhesión, pudiendo influir el mismo material, su rugosidad o su energía superficial.

\section{BIBLIOGRAFÍA}

1. Stewart L, Smith AL, Pellegrini CA: Pigment gallstones form as a composite of bacterial microcolonies and pigment solids. Ann Surg, 1987. 206 (3): 242-50.

2. Pascual, A: Interacción entre microorganismos, materiales y antimicrobianos. Conferencia de Consenso "infección por cateter en U.C.I." SEMIUC. 1996, I-25-34.
3. Quirynen M, Bollen L: The influence of surface roughness and surface-free energy on supraand subgingival plaque formation in man. J Clin Periodontol 1995; 22: 1-14.

4. Absolom, DR: The role of bacterial hydrophobicity in infection: bacterial adhesion and phagocytic ingestion. Canadan J Microbiol. 1988; 34: 287-98.

5. Gibbons RJ, Cohen L, Hay DI: Strain of Streptococcus mutans and Streptococcus sobrinus attach to differnts pelicle receptors. Infect Inmum. 1986; 52: 555-61.

6. Kawai K, Murano M: Adherence of plaque components to different restorative materials. Oper Dent. 2001; 26: 396-400.

7. Quirynen $M$, marechal $M$, Busscher $\mathrm{H}$ : The influence of surface free energy and surface roughness on early plaque formation. J Clin periodontol. 1990; 17: 138-44.

8. Shahal Y, Steinberg D, Hirschfeld Z: In vitro bacterial adherence onto pellicle-coated aesthetic restorative materials. J Oral Rehabil. 1998; 25 (1): 52-8.

9. Palenik CJ, Behnen MJ, Setcos JC : Inhibition of microbial adherence and growth by varios glass ionomers in vitro. Dent Mater. 1992; 8 (1):16-20

10. Imazato S, Torii M, Tsuchitani Y: Antibacterial effect of composite incorporating Triclosan against Streptococcus mutans. J Osaka Univ Dent Sch. 1995; 35: 5-11.

11. Carlen A, Nikdel K, Wennerberg A: Surface Characteristics and in vitro biofilm formation on glass ionomer and composite resin. Biomaterials. 2001; 22 (5): 481-7.

12. Yamamoto K, Ohashi S, Taki E. Adherence of oral streptococci to composite resin of varing surface roughness. Dent Mater. 1996; 15 (2): 201-4.

13. Mor C, Steinberg D, Dogan H: Bacterial adhe- 
rence to bleaches surfaces of composite resin in vitro. Oral Surg oral Med oral Pathol Oral radiol Endod. 1998; 86 (5): 582-6.

14. Hyypra T, Paunio K: Tha plaque-inhibiting effect of copper amalgam. J Clin Periodontol. 1977; 4 (4): 231-9.
15. Adamczyk E, Spiechowicz E: Plaque accumulation on crowns made of various materials. In $\mathrm{J}$ Prosthodont. 1990; 3 (3): 285-91. 